\title{
Motivação ambiente de trabalho - um estudo de casos na Associação de Pais e Amigos dos Excepcionais de Dianópolis (APAE)
}

\author{
Work environmental motivation - a case study at the Association of Parents and Friends of the \\ Exceptional in Dianópolis (APAE) \\ Motivación ambiental laboral - estudio de caso en la Asociación de Padres y Amigos de los \\ Excepcionales de Dianópolis (APAE)
}

\author{
Thaíse Torres de Albuquerque \\ ORCID: https://orcid.org/0000-0002-2984-6785 \\ Universidade Estadual do Tocantins, Brasil \\ E-mail:prisilva7@outlook.com \\ Marcos José de Almeida Matias \\ ORCID: https://orcid.org/0000-0002-0643-9941 \\ Universidade Estadual do Tocantins, Brasil \\ E-mail: marcos.ja@unitins.br \\ Mônica de Souza Lima \\ ORCID: https://orcid.org/0000-0003-4457-2011 \\ Universidade Estadual do Tocantins, Brasil \\ E-mail: monica.contadora@yahoo.com.br \\ Denise Barros de Azevedo \\ ORCID: https://orcid.org/0000-0003-0253-8616 \\ Universidade Federal do Mato Grosso do Sul, Brasil \\ E-mail: deniseazevedo1972@gmail.com
}

\begin{abstract}
Resumo
A motivação no ambiente de trabalho vem se popularizando entre as empresas em busca de uma boa qualidade de vida de seus colaboradores, visando um bom rendimento e lucratividade para a empresa. O presente estudo tem como objetivo geral é analisar a motivação no ambiente de trabalho dos colaboradores da Associação de Pais e Amigos dos Excepcionais de Dianópolis (APAE), com relação ao ambiente de trabalho. Essa pesquisa se predomina, qualitativa e quantitativa pois, o propósito da pesquisa é analisar o grau de motivação dos colaboradores e envolve uma coleta de dados com acesso a documentos que foi disponibilizado pela empresa para a pesquisadora, o questionário com sete perguntas será aplicado para 31 servidores entre eles, professores de primeiro ao quinto ano, professores do primeiro e segundo seguimento de EJA, coordenadores, secretaria, diretor, auxiliar de serviços gerais, vigias, cozinheira e motoristas da Associação de Pais e Amigos dos Excepcionais (APAE), com o intuito de identificar os fatores que não contribuem para a motivação dos colaboradores, realizado no período de março a outubro de 2020. Diante dessa pesquisa, foi possível visualizar que a hipótese levantada no início deste trabalho foi confirmada parcialmente, pois os demais respondentes estão satisfeitos com ambiente mas não estão 100\% satisfeitos com seus colegas de trabalho, tendo ai um conflito a ser resolvido pela instituição.
\end{abstract}

Palavras-chave: Motivação no ambiente de trabalho; Satisfação do colaborador; Qualidade de vida.

\begin{abstract}
Motivation in the work environment has become popular among companies in search of a good quality of life for their employees, aiming at a good performance and profitability for the company. The present study has the general objective of analyzing the motivation in the work environment of the employees of the Association of Parents and Friends of the Exceptional of Dianópolis (APAE), in relation to the work environment. This research is predominant, qualitative and quantitative because the purpose of the research is to analyze the degree of motivation of the collaborators and involves a data collection with access to documents that was made available by the company to the researcher, the questionnaire with seven questions will be applied to 31 among them, teachers from the first to the fifth year, teachers from the first and second segment of EJA, coordinators, secretary, director, general services assistant, watchmen, cook and drivers of the Association of Parents and Friends of the Exceptional (APAE), with the in order to identify the factors that do not contribute to the motivation of employees, carried out from March to October 2020. In view of this research, it was possible to see that the hypothesis raised at the beginning of this work was partially confirmed, since the other respondents are satisfied with environment but are not $100 \%$ satisfied with their co-workers, and there is a conflict to be resolved by the institution.
\end{abstract}

Keywords: Motivation in the work environment; Employee satisfaction; Quality of life. 


\begin{abstract}
Resumen
La motivación en el entorno laboral se ha popularizado entre las empresas en busca de una buena calidad de vida para sus empleados, con el objetivo de un buen desempeño y rentabilidad para la empresa. El presente estudio tiene como objetivo general analizar la motivación en el clima laboral de los empleados de la Asociación de Padres y Amigos de los Excepcionales de Dianópolis (APAE), en relación al clima laboral. Esta investigación es predominante, cualitativa y cuantitativa porque el propósito de la investigación es analizar el grado de motivación de los colaboradores e involucra una recolección de datos con acceso a documentos que fue puesto a disposición por la empresa al investigador, el cuestionario con siete preguntas será Se aplicará a 31 de ellos, docentes de primer a quinto año, docentes del primer y segundo segmento de EJA, coordinadores, secretaria, directora, auxiliar de servicios generales, vigilantes, cocinera y choferes de la Asociación de Padres y Amigos de la Excepcional (APAE), con el fin de identificar los factores que no contribuyen a la motivación de los empleados, realizado de marzo a octubre de 2020. A la vista de esta investigación, se pudo constatar que la hipótesis planteada al inicio de Este trabajo fue parcialmente confirmado, ya que los otros encuestados están satisfechos con el medio ambiente pero no están 100\% satisfechos con sus compañeros de trabajo, y existe un conflicto que debe resolver La institución.
\end{abstract}

Palabras clave: Motivación en el entorno laboral; Satisfacción del empleado; Calidad de vida.

\title{
1. Introdução
}

No contexto atual em que a vida profissional é cheia de desafios e de competições, estar motivado é uma condição para realizar diversas tarefas, sejam elas corriqueiras ou excepcionais e se faz essencial fazer parte das opiniões dos colaboradores em suas ações e motivar a agir em prol de seus objetivos de suas vontades próprias que surgem de acordo com suas necessidades. Para Herzberg (2000), o autor da teoria do dois fatores que aborda a situação de motivação e satisfação, essa teoria tem como objetivo medir a insatisfação do colaborador no ambiente de trabalho e discriminar quais os fatores que estaria causando tamanha insatisfação.

De acordo com que foi exposto, Garcia e Ramos (2019), reforça a necessidade da motivação no ambiente de trabalho quando se trata do Atendimento Educacional Especializado. Dessa forma a motivação é importante pois o colaborador trabalha satisfeito em seu ambiente de trabalho e estando também satisfeito com suas necessidades individuais, com isso vai exercer suas atividades de forma eficiente e cumprir com suas metas (Robins, 2007).

Dessa forma surgiu a seguinte problemática: Como é a motivação dos colaboradores em relação ao ambiente de trabalho, na Associação de Pais e Amigos dos Excepcionais (APAE)? Com a hipótese o ambiente de trabalho influencia a motivação dos colaboradores. Sendo assim o objetivo geral dessa pesquisa é analisar a motivação dos colaboradores na Associação de Pais e Amigos dos Excepcionais (APAE).

Essa pesquisa se justifica pois, de acordo com os resultados podemos analisar o grau de satisfação e motivação dos colaboradores com relação ao trabalho exercido na Associação de Pais e Amigos dos Excepcionais (APAE) de Dianópolis.

\section{Referencial Teórico}

\subsection{A motivação conceitos e definições}

De acordo com Maslow (1908), a motivação no ambiente de trabalho torna-se um enorme desafio aos que acredita na qualidade, com a participação de diversos segmentos dentro da organização e que se considera um desafio na construção de um processo gerencial determinado pelo modelo sócio-político e ideológico instituído pela sociedade capitalista dominante.

Defende ainda que o ambiente de trabalho é fundamental que todos possam sesentirem satisfeitos com as atividades que desenvolvem e ainda fazer o melhor e da melhor forma, de modo a ser em pequenas ou grandes proporções demonstrando seus avanços e atingindo diferentes necessidades que estimulam e entusiasmam as pessoas para o trabalho e que a motivação humana é um tema que vem a ser estudado, devido à sua complexidade e os impactos que causam aos indivíduos no ambiente profissional ( Maslow, 1943).

Motivação significa mover, fazer e tem como objetivo incentivar e estimular o comportamento humano que acaba energizado por algum tipo de motivo ou razão. O comportamento humano sempre é motivado, sempre haverá um motivo para o 
indivíduo se sentir motivado e continuar exercendo seu trabalho com satisfação (Maximiano, 2006).

Alguns fatores analisados por Schermerhorn, Hunt e Osborn (1998), definem a motivação como as forças de dentro de uma pessoa responsáveis pelo nível, direção e persistência do esforço despedido no trabalho. A importância da motivação no ambiente de trabalho faz-se compreender que os aspectos motivacionais, movem as pessoas a determinado destino com determinados objetivos a serem alcançados, estimulando a produtividade e suas interações aos valores e aspirações.

Segundo Oliveira (2005), sentir-se satisfeito é essencial para o bom desempenho dos seus colaboradores, sendo evidenciado que um dos motores propulsores que movem as pessoas é a motivação, ou seja, ter motivos para buscar atingir seus determinados objetivos e metas, com satisfação e entusiasmo. Quando os fatores motivacionais são otimizados, elevam a satisfação, ao contrário disso provocará descontentamento e a não realização pessoal e profissional. Uma vez que a motivação é a energia biológica, física e mental é intrínseca do indivíduo, que somada aos inúmeros estímulos ambientais e sociais, levam o homem a procurar um objetivo para satisfazer em curto, médio e longos prazos.

Complementa ainda o autor Maslow (1965), diz que o termo motivação envolve sentimentos de realização, de crescimento e de reconhecimento profissional, manifestados por meio dos exercícios e das tarefas e atividades que ofereçam desafios e significados para o trabalho. As organizações, que de alguma forma conseguiram identificar a origem da motivação de seus colaboradores devem usar deste trabalho no sentido de aperfeiçoar ou buscar sempre estratégias de motivação dos mesmos, de forma a aumentar as potencialidades, de seus colaboradores e utilizar como um importante recurso, as pessoas.

\subsection{A motivação profissional e o ambiente de trabalho}

Para Gil (2001), o mundo atual e a inovação surge a cada momento de forma acelerada que transformam o cotidiano do homem, como as novas tecnologias que exigem uma maior qualificação, maior conhecimento e uma visão ampla da realidade em que está inserido e precisam atualizar-se, constantemente, uma vez que há uma dinâmica cada vez maior, com um mercado que exige mais e mais qualidade na produção e na prestação de serviços.

Nesse sentido, o ambiente de trabalho pode ser prejudicado por tantas mudanças se tornando um grande desafio para as organizações. O sucesso das organizações e das pessoas que as fazem funcionarem não vem fácil. Essa era de contrastes abre a porta para a criatividade na administração, no mundo atual a atmosfera competitiva vem crescendo a cada dia e as tecnologias cada vez mais inovadoras e complexas que necessita de pessoas capacitadas e motivadas para exercerem da melhor forma e com eficiência. E para que a empresa eleve seu desempenho precisa de colaboradores bem motivados e entusiasmado (Hunt \& Osborn, 1998).

Nesse sentido Gil (2001), por sua vez entende que as pessoas podem ampliar ou limitar as forças e fraquezas de uma organização, dependendo da maneira como elas são tratadas, e de que forma os objetivos são alcançados, devendo ser levado em consideração que numa organização as pessoas são elementos básicos para a eficiência e eficácia, sendo considerado um dos recursos mais importante e estruturante para o sucesso organizacional desejado e para que isso seja possível é preciso exercitar a motivação dos empregados na empresa. A identificação de quem está motivado e quem não está. Para tanto a observação do comportamento manifestado pelas pessoas constitui, no desenvolvimento e produção do indivíduo na maioria dos casos, e devem ser observado também os gestos, postura e pode permitir de alguma forma identificar seu grau de motivação.

Vergara (2000), por sua vez, afirma que o comportamento das pessoas varia em decorrência de diferentes motivações, o que motiva uma pessoa pode não motivar a outra, o que motiva em determinado momento, pode não motivar em outro. Isso é o que diferencia uma pessoa da outra. $O$ desempenho de uma organização depende fortemente da contribuição das pessoas que a compõem e da forma como elas estão organizadas, são estimuladas e capacitadas, e como são mantidas num ambiente de trabalho e num clima organizacional adequados.

A partir dessa reflexão, pode se dizer que as pessoas quando estimuladas, validadas se sentem motivadas a produzirem 
muito mais e com qualidade. Neste caso o processo motivacional individual busca a manutenção do equilíbrio, sendo que a energia usada para este, vem da capacidade de cada um se auto motivar, a qual é desenvolvida ao longo do tempo (Castro, 2002).

\subsection{As teorias que envolvem a motivação nas organizações}

\subsubsection{Hierarquia das necessidades de Maslow}

Sobre este enfoque, segundo Maslow (1970), diz que o trabalho com pessoas envolve várias necessidades, sendo de fundamental importância a compreensão do contexto global em que se está inserido, além de saber que cada indivíduo envolvido numa organização tem toda uma história, e vem de uma determinada cultura, tem seus interesses e suas dificuldades psicossociais. Além da influência exercida pelos líderes, existem diversas necessidades que estimulam as pessoas para o trabalho. Maslow hierarquizou essas necessidades em cinco níveis de influência: A base da pirâmide aponta as necessidades de nível mais baixo, que são as fisiológicas e as de segurança, enquanto no topo são apontadas as necessidades de nível alto, que são o resultado a busca pela individualização do ser, que são as necessidades sociais, de estima e de auto realização.

Conforme a Piramide das necessidades, Robbins (2005), apresenta a definição para cada uma das cinco categorias de necessidades, sendo elas:

1- Necessidades Fisiológicas, são as necessidades básicas de sobrevivência do indivíduo;

2- Necessidades de Segurança, são as necessidades de proteção de estar livre de perigos contra danos físicos e emocionais;

3- Necessidades Sociais, é a aceitação e sensação de pertencer a um grupo;

4- Necessidades de Estima, relacionado ao auto respeito, amor próprio e status;

5- Necessidades de Auto Realização, compreende as ações que nos realizam de forma pessoal e única, através da realização pessoal, crescimento e sentimentos de prazer.

Nesse sentido os autores, Schermerhorn, Hunt e Osborn (1998), afirmaram que as teorias ajudam a explicar por que o mau desempenho, atrasos, faltas, baixo nível de esforço, mau comportamento, entre outros problemas, podem ser causados por necessidades que são bloqueadas diretamente ou não atendidas no trabalho. Também nos ajudam a avaliar o valor motivacional das recompensas com base na sua capacidade de resposta a importantes necessidades que um indivíduo procura satisfazer. Desde o momento em que se detecta a necessidade de pessoas para, a estrutura organizacional, é preciso atuar e minimizar as percepções distorcidas tanto por parte dos que estão na organização quanto pelos que se relacionam direta ou indiretamente com a mesma, buscando parceiras na seleção de pessoas dotadas de inteligência e criatividade, que podem levar as organizações a alcançar patamares jamais imagináveis sem participação e o comprometimento de todos.

\subsubsection{Teoria X e Y de Douglas McGregor}

Na opinião do autor, McGregor (1964), compara dois estilos opostos e antagônicos de administrar conforme cita Chiavenato (2002). Uma teoria fundamenta-se em convicções erradas sobre o comportamento das pessoas, e outra se baseia sem preconceitos a respeito da natureza humana.

De acordo com a Quadro 1- Teoria X e Y, o autor Chiavenato (2002) ressalta o comportamento dos humano nas organizações empresariais e tem como finalidade representar as diferentes atitudes que agrupam diferentes concepções e práticas. 
Quadro 1 - Teoria X e Y.

\begin{tabular}{|c|c|}
\hline Teoria X & Teoria Y \\
\hline As pessoas são preguiçosas e & As pessoas são esforçadas e gostam de ter o que fazer \\
indolentes. & O trabalho é uma atividade tão natural como brincar ou descansar \\
\hline As pessoas evitam o trabalho & As pessoas procuram e aceitam responsabilidades e desafios \\
\hline As pessoas evitam a responsabilidade & As pessoas podem ser automotivas e autodirigidas. \\
\hline As pessoas precisam ser controladas e & As pessoas são criativas e competentes \\
\hline dirigidas. & \\
\hline As pessoas são ingênuas e sem & \\
\hline
\end{tabular}

Fonte: adaptado de Chiavenato (2002).

\subsubsection{Teoria dos dois fatores de Herzberg}

Der acordo com o autor, Herzberg (2003), que elaborou a Teoria dos Dois Fatores, que fundamenta a pirâmide das necessidades de Chiavenato (2002), percebendo que os fatores que causam satisfação no trabalho são diferentes dos que levam a insatisfação, o autor criou a teoria dos dois fatores.

Os Fatores Higiênicos que são os de manutenção, presentes no ambiente da empresa como relacionamento com os colegas, condições físicas do trabalho, relacionamento superior/subordinado, segurança, salário entre outros. Esses fatores são apenas suficientes para que os colaboradores não fiquem insatisfeitos, mas não aumentam a satisfação das pessoas.

Já os Fatores Motivacionais que relacionam o conteúdo do cargo e do trabalho realizado, esse fator tem o poder de gerar um estado de satisfação, a responsabilidade, reconhecimento, autonomia, realização pessoal e profissional entre outros são algumas variáveis dos fatores (Chianenato, 2002).

Nesse sentido, Maciel e Sá (2007), afirma que quando deparamos com colaboradores insatisfeitos, que venha a se apresentar desmotivado, isso atrapalha no esforço em empreender os seus conhecimento e habilidades pessoais para a realização dos trabalhos. A falta de motivação no trabalho é algo que há anos vem afligindo as pessoas nas organizações. Os efeitos da desmotivação no trabalho podem gerar graves problemas tanto para as organizações quanto para as pessoas.

Segundo Chiavenato (2008), afirma que toda empresa possui um clima organizacional interno próprio, que está interligado com a satisfação, insatisfação, ideologias, ética e moral da empresa, o que se faz positivo e negativo com relação ao ponto de vista da instituição e seus colaboradores.

Complementa ainda o autor Maximiano (2006), que o clima organizacional é a essência de como os seus colaboradores se sentem com relação a instituição em que prestam serviço e seus superiores, se for um índice positivo a empresa tende a evoluir o seu índice para um patamar de qualidade e eficácia. Nesse sentido os autores Ferreira, Fortuna e Tachizawa (2006), destaca ainda que a empresa é a maior influenciadora de seus colaboradores e que o clima organizacional é a qualidade da empresa.

Já Aydin (2012), diz que a desmotivação influência nos resultados da produtividade bem como, pode transparecer um ambiente negativo e gerar insatisfação nas pessoas e afirma ainda que a sobrecarga de atividades afeta o rendimento, gerando insatisfação nas pessoas. É de grande importância que a organização valorize os seus funcionários, de maneira que possa manter um lugar de destaque no atual mercado competitivo e que desenvolvam da melhor forma, de modo a ser em pequenas ou grandes proporções demonstrando seus avanços e atingindo diferentes necessidades que estimulam e entusiasmem as pessoas para o trabalho. 
Sob este enfoque, segundo Cabral (2014), lembra que as necessidades humanas nem sempre são supridas, levando a sentimento de frustração, agressividade, baixa autoestima, pessimismo, resistência a novidades e a insegurança. Isso poderá levar o funcionário à desmotivação.

Diante disto, complementa ainda os autores Oliveira (2009) e Aydin (2012) retratam que a remuneração é um fator preponderante. Para eles pessoas que recebem mal se sentem desmotivadas e isto interfere no rendimento dele na empresa. Assim, no que se refere às políticas e práticas necessárias para se administrar o trabalho das pessoas é basicamente agregar valores, fundamentais ao desenvolvimento dos trabalhos de forma a orientar e acompanhar as pessoas, avaliando seu desempenho e as recompensar como: salários, prêmios, benefícios e serviços sociais e proporcionar treinamentos dando suporte para que as pessoas se sintam bem dentro da organização.

\section{Metodologia da Pesquisa}

A pesquisa é classificada como: bibliográfica, documental, descritiva e um estudo de campo de acordo com Gil (2008) uma vez que o objetivo geral dessa pesquisa é analisar a motivação dos colaboradores da Associação de Pais e Amigos dos Excepcionais (APAE), de Dianópolis-TO.

Então, o desenvolvimento da pesquisa foi de forma qualitativa e quantitativa, sob este enfoque, segundo Silva e Menezes (2001) tudo pode se traduzir em números, como opiniões e informações, em vista disso permite ser melhor para classificar e analisar os dados, mas para obter os resultados requer o uso de técnicas e estatísticas. Uma vez que o propósito da pesquisa é analisar o grau de motivação dos colaboradores e envolve uma coleta de dados com acesso a documentos que foi disponibilizado pela empresa. Já o questionário com sete perguntas foi aplicado para 31 servidores entre eles, professores de primeiro ao quinto ano, professores do primeiro e segundo seguimento de EJA, coordenadores, secretaria, diretor, auxiliar de serviços gerais, vigias, cozinheira e motoristas da Associação de Pais e Amigos dos Excepcionais (APAE), com o intuito de identificar os fatores que não contribuem para a motivação dos colaboradores.

Inicialmente foi feito um contato via whatsapp com os 31 servidores, onde 16 servidores se dispuseram a responder o questionário voluntariamente via google forms, onde os demais responderam com facilidade e expuseram seu ponto de vista com relação a associação.É, também uma pesquisa descritiva, pois tem como característica medir o grau de satisfação dos servidores com relação ao trabalho prestado, e estudo de campo pois a pesquisa busca observar, analisar e interpretar os fatos e fenômenos que ocorre no ambiente.

Para análise dos dados, foi feita a estatística dos dados dos colaboradores que dispuseram a responder o questionário e analisando os resultados de acordo com as respostas referidas de cada servidor.

\section{Resultados e Discussão}

\subsection{Histórico de implantação da empresa}

A APAE-Escola Especial Colibri está situada na Rua de Janeiro s/nº no Setor Brasil, cidade de Dianópolis/TO. Recebeu esse nome pelos seus fundadores, baseando-se na fábula que conta a atitude de um pássaro chamado Colibri. Incentivados pela atitude deste pequeno pássaro, os fundadores da Escola Especial Colibri não se intimidaram e durante muitos anos lutaram pela sua criação.

A referida escola é uma instituição que atende a clientela da APAE- Associação de Pais e Amigos dos Excepcionais de Dianópolis. Foi declarada Utilidade Pública Estadual pela Lei n ${ }^{\circ}$.992, de 9 de dezembro de 2008. A Associação é inscrita no CNPJ n 05.645.149/0001- 41, presidida por Maria Jane Barbosa de Melo que exerce relevante trabalho junto á direção da Unidade Escolar. É mantida pela associação, pelo Estado e pela Prefeitura Municipal. Pela associação: os associados contribuem com R \$ 10,00 (dez reais) mensalmente; a Prefeitura Municipal cede de 04 (quatro) servidores ( 03 professores e uma auxiliar de 
serviços gerais); o Estado cede 31 servidores. É uma escola de portas abertas para acolher quem tem necessidade de frequentála, reconhecendo os benefícios que ela propicia inclusive melhoramento na qualidade de vida. Nesta perspectiva ainda há um aliado (que a instituição muito agradece), o Poder Judiciário, que também auxilia com cestas básicas, adquiridas pelo cumprimento de penas alternativas.

A escola já está em atividade há dez anos oferecendo o Ensino Fundamental, séries iniciais e a Educação de Jovens e Adultos, $1^{\circ} \mathrm{e} 2^{\circ}$ segmento nos períodos matutino e vespertino. Existem 79 (setenta e nove) alunos matriculados em escolarização e oficinas pedagógicas. A escola funciona num prédio cedido pelo estado do Tocantins e que, dentro das possibilidades, foi adaptada para atender as necessidades dos alunos. A Prefeitura Municipal de Dianópolis fez uma doação de um lote para a Escola Especial Colibri, conforme Lei de doação no 1304/2014, área urbana, localizada na Gleba 013 no Setor Industrial, onde futuramente será construída a sede própria da instituição.

A escola adota a Estrutura Curricular e Regimento padrão da SEDUC/TO, pois a mesma pertence a rede Estadual de Educação. A pesquisa foi destinada a todos os setores das Associação de Pais e Amigos dos Excepcionais (APAE) de Dianópolis, dentre eles, professores de primeiro ao quinto ano, professores do primeiro e segundo seguimento de EJA, coordenadores, secretaria, diretor, auxiliar de serviços gerais, vigias, cozinheira e motoristas.

O Quadro 2 abaixo, mostra a quantidade de servidores e suas funções e cargo de onde cada servidor atua.

Quadro 2 - Funções e cargos de servidores.

\begin{tabular}{|c|c|c|}
\hline $\mathbf{N}^{\mathbf{0}}$ & Quantidade & Função/ Cargo \\
\hline 01 & 01 & Coordenação Pedagógica \\
\hline 02 & 06 & Monitora Educacional \\
\hline 03 & 05 & Professora \\
\hline 04 & 02 & Merendeira \\
\hline 05 & 03 & Auxiliar De Serviços Gerais \\
\hline 06 & 03 & Motorista \\
\hline 07 & 01 & Coordenadora De Oficina \\
\hline 08 & 01 & Gestora \\
\hline 09 & 01 & Secretaria Geral \\
\hline 10 & 01 & Coord. De Apoio Financeiro \\
\hline 11 & 01 & Professor \\
\hline 12 & 01 & Gestora \\
\hline 13 & 01 & Secretaria Geral \\
\hline 14 & 03 & Vigia \\
\hline 15 & 01 & Professor Auxiliar \\
\hline
\end{tabular}

Fonte: Adaptado om base nos dados coletados

Tendo em vista essa grade de servidor, nota-se que a maior parte são professores, contabilizando 5 professoras, 1 professor, 1 professor auxiliar e 6 monitores educacionais que exerce a mesma função que o professor, totalizando 13 servidores que tem contato direto com os alunos em sala de aula.

Diante desse pressuposto e por dados coletados na empresa, analisamos também que a maioria da empresa é composta por pessoas do sexo feminino, totalizando 23 servidoras do sexo feminino e 8 servidores do sexo masculino entre eles professor, professor auxiliar, vigias e motoristas. 
Figura 1 - Estimativa do grau de escolaridade dos colaboradores.
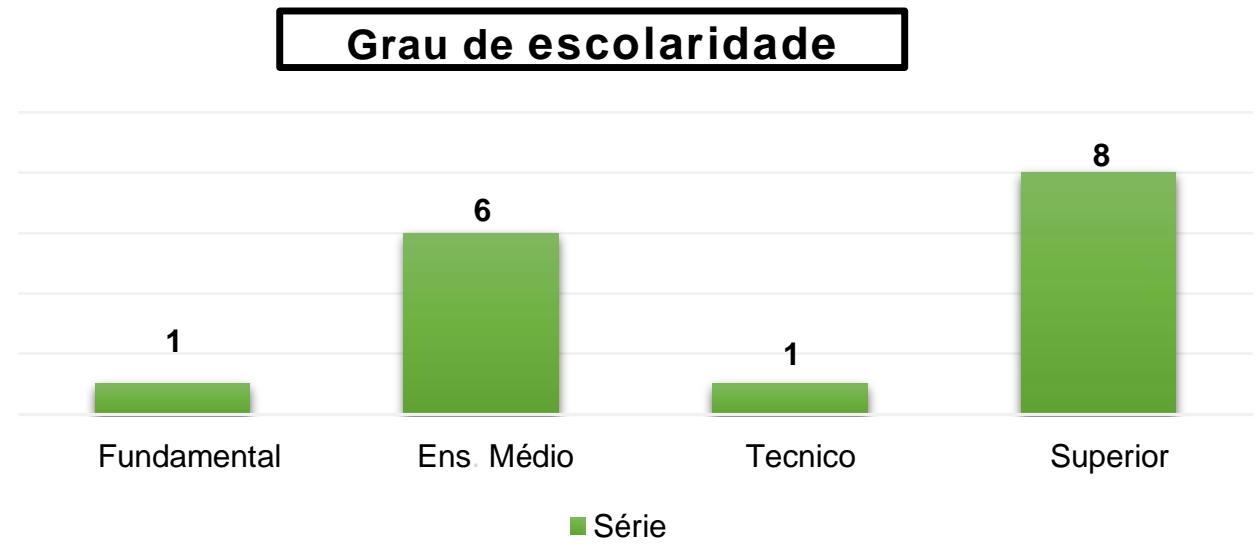

Fonte: Adaptado om base nos dados coletados.

De acordo com os dados coletados via Google Forms notamos na figura 4, que boa parte dos servidores possuem um grau de escolaridade superior, contendo 8 servidores graduados, 1 técnico, 6 possuem ensino médio e 1 somente com o ensino fundamental.

Os servidores que possuem ensino superior são os coordenadores, professores, gestora, secretaria, monitoras educacionais e uma auxiliar de serviços gerais, e os de ensino médio são os monitores educacionais, vigias, merendeiras, auxiliar de serviços gerais e motoristas en apenas 1 vigia que possui apenas o ensino fundamental e uma monitora educacional que possui o técnico.

Com base no trabalho em execução, com dados coletados na empresa o tema que tem como objetivo analisar a motivação no ambiente de trabalho, descrevemos vários pontos que é capaz de levar um indivíduo a se auto motivar e várias citações de autores que defendem essa causa.

Segundo Chiavenato (2008), afirma que toda empresa possui um clima organizacional interno próprio, que está interligado com a satisfação, insatisfação, ideologias, ética e moral da empresa, o que se faz positivo e negativo com relação ao ponto de vista da instituição e seus colaboradores.

Complementa ainda o autor Maximiano (2006), que o clima organizacional é a essência de como os seus colaboradores se sentem com relação a instituição em que prestam serviço e seus superiores, se for um índice positivo a empresa tende a evoluir o seu índice para um patamar de qualidade e eficácia.

Nesse sentido os autores Ferreira, Fortuna e Tachizawa (2006), destaca ainda que a empresa é a maior influenciadora de seus colaboradores e que o clima organizacional é a qualidade da empresa.

Diante dos dados apresentados, com média de 31 servidores na instituição, apenas 16 me responderam o questionário voluntariamente e com base nesses 16 servidores pude observar o grau de motivação e satisfação no seu ambiente de trabalho.

Com isso a Figura 2 mostra a porcentagem do grau de satisfação dos colaboradores com relação ao serviço prestado, com relação aos seus superiores e ao ambiente de trabalho. 
Figura 2 - Satisfação com relação ao ambiente de trabalho, colegas e seus superiores.

\begin{tabular}{|c|c|c|c|c|}
\hline Item & Insatisfeito & $\begin{array}{l}\text { Nem satisfeito/ } \\
\text { Nem insatisfeito }\end{array}$ & Satisfeito & $\begin{array}{r}\text { Muito } \\
\text { satisfeito }\end{array}$ \\
\hline $\begin{array}{l}\text { Quão satisfeito você está com } \\
\text { seu local de trabalho? }\end{array}$ & & $10 \%$ & $70 \%$ & $20 \%$ \\
\hline $\begin{array}{l}\text { O quanto seu trabalho atual } \\
\text { satisfaz suas expectativas? }\end{array}$ & & $16,67 \%$ & $66,66 \%$ & $16,67 \%$ \\
\hline $\begin{array}{r}\text { Quão próximo é o seu local de } \\
\text { trabalho do ideal? }\end{array}$ & & $16,67 \%$ & $66,64 \%$ & $16,69 \%$ \\
\hline $\begin{array}{r}\text { Está satisfeito com os seus } \\
\text { colegas de trabalho? }\end{array}$ & $16,56 \%$ & $16,67 \%$ & $16,67 \%$ & $50,10 \%$ \\
\hline $\begin{array}{r}\text { Relacionamento do superior } \\
\text { com você? }\end{array}$ & & $33,33 \%$ & & $66,67 \%$ \\
\hline $\begin{array}{r}\text { Está satisfeito com a natureza } \\
\text { do seu trabalho? }\end{array}$ & & $10 \%$ & $10 \%$ & $80 \%$ \\
\hline
\end{tabular}

Fonte: Elaborado pela pesquisadora.

De acordo com a Figura 2, percebe-se que os colaboradores da Associação de Pais e Amigos dos Excepcionais a maioria estão satisfeitos e muito satisfeitos com o local de trabalho, com os colegas, com o trabalho que exerce e com os seus superiores, mas percebe-se também que alguns colaboradores se manifestaram nem satisfeitos nem insatisfeitos com relação ao ambiente de trabalho e seus superiores e 16,56\% diz estar insatisfeito com seus colegas de trabalho.

Os resultados coletados envolvendo a satisfação geraram respostas neutras entre os colaboradores, pois boa parte deles percebem o reconhecimento, o valor e a disponibilidade que a supervisão e a empresa demonstram, porém a outra parte obteve respostas neutras, ou seja, nem todos estão sendo alcançados por esse fator que deveria ser motivacional.

Então compreende que o clima organizacional é estabilizado com relação a pesquisa, mas há um lado preocupante com o grupo que se manifestaram neutros, que não estão satisfeitos e nem insatisfeitos e os 16,56\% que não estão satisfeitos com os colegas de trabalho, issopode ocasionar um conflito na empresa.

Outro ponto importante, o salário leva o funcionário a exercer seu trabalho com satisfação, diante de diversos fatos, sabemos que somente o piso salarial alto, não leva nenhum colaborador a satisfação e a motivação dentro da empresa, dependem de diversos quesitos para leva-los a um grau de satisfação e exercer seu trabalho com eficiência e eficácia.

Mas a remuneração deve ser adequada ao estilo de trabalho prestado e que ele supra adequadamente com as necessidades pessoais dos padrões econômicos do colaborador.

Segundo Santos (2012), diz que a remuneração adequada se faz necessário para suprir as necessidades pessoais, sociais e culturais da sociedade em que o servidor está inserido, a remuneração deve ser satisfatória para que o relacionamento do colaborador e instituição seja adequadas.

Observou-se que a maioria dos servidores estão insatisfeitos com a remuneração salarial, somente 16,67\% está satisfeito e $83,33 \%$ acha que deve melhorar, essa insatisfação leva o servidor a trabalhar desmotivado e os respondentes referem sobre a remuneração em comparação com as dos colaboradores efetivos, pois exercem o mesma função e recebem a metade da remuneração de um servidor efetivo.

Diante dos dados coletados observa-se que a maior parte dos servidores respondentes não estão satisfeito com o salário, acham que deve melhorar, uma das justificativas foi que os mesmo com formação acadêmica recebem salário inferior aos demais, tudo isso com base em um acordo feito entre a Associação de Pais e Amigos dos Excepcionais (APAE) e o governo do estado, para contratarem servidores capacitados para assumir uma sala de aula e serem contratados com cargos diferentes no caso 
Monitor educacional.

Com isso, percebemos que a falta de motivação está em exercer a mesma função e receber um salário inferior e alguns desacordos entre colegas de trabalho, no mais vemos que o ambiente é propicio e de bom acesso, tem as necessidades fisiológicas, segurança e social equilibradas e um ambiente acolhedor e divertido.

\section{Considerações Finais}

Concluindo o trabalho, retomam-se os objetivos iniciais para apresentar a análise em relação a seus resultados tendo como parâmetro o problema e hipótese proposto no inicia da pesquisa. O objetivo desse trabalho foi, analisar como é motivação dos colaboradores em relação ao ambiente de trabalho, na Associação de Pais e Amigos dos Excepcionais (APAE) de DianopolisTO? Com a hipótese o ambiente de trabalho influencia a motivação dos colaboradores.

Para alcançar o objetivo específico central da pesquisa, se fez necessário visitas a instituição pesquisada, onde tive acesso a documentos da instituição fornecido voluntariamente pela secretaria com autorização da gestora escolar e também usou-se o questionário com sete perguntas direcionado a todos os 31 servidores onde apenas 16 responderam voluntariamente. Dessa forma, os objetivos propostos foram atingidos e pode-se responder à pergunta apresentada no início deste trabalho, Como a motivação dos colaboradores tem relação com ambiente de trabalho, na Associação de Pais e Amigos dos Excepcionais (APAE) de Dianopolis-TO?

Nesse estudo, constatou-se que: alguns colaboradores não estão satisfeitos com o seu piso salario e tem algumas divergências com alguns colegas de profissão, mas que estão satisfeitos com o trabalho exercido, com os superiores e com o ambiente de trabalho, pois ate o momento os conflitos entre colegas foi bem gesticulado e administrado da melhor forma pelos superiores. Pode-se observar que os colaboradores dependem de um ambiente harmonioso, seguro e que atendem suas necessidades fisiológicas.

Mas também, hipótese levantada no início deste trabalho, o ambiente de trabalho influencia a motivação dos colaboradores. E pela pesquisa é possível observar que o ambiente é um dos principais influenciadores para motivação de seus colaboradores, se o ambiente não é harmonioso e transmita segurança o colaborador vai ter dificuldades de exercer o seu trabalho com eficácia e eficiência.

No estudo de casos, realizado na Associação de Pais e Amigos dos Excepcionais (APAE) de Dianopolis-TO, foi possível visualizar que a hipótese levantada no início deste trabalho foi confirmada parcialmente, pois os demais respondentes estão satisfeitos com ambiente mas não estão 100\% satisfeitos com seus colegas de trabalho, tendo ai um conflito a ser resolvido pela instituição.

Observa-se que, embora tendo esse conflito entre colaboradores da instituição, que pode ser solucionado rapidamente pelo seu gestor, o ambiente é tranquilo.

Portanto, com o término deste trabalho, foi possível identificar elementos que podem ser aprofundados em pesquisas futuras. Nesse sentido, recomenda-se que seja executada pesquisas científicas e trabalhos acadêmicos, para analisar com maior profundidade o fenômeno da motivação no ambiente de trabalho.

Vale salientar que o desdobramento deste estudo contribuirá para uma reflexão dos gestores de empresas de Dianópolis e Região, sobre como se dá o processo de motivação das pessoas no ambiente de trabalho.

\section{Referências}

Aydin, S. (2012). Factors Causing Demotivation in EFL Teaching Process: A Case Study. Qualitative Report, Networks.nova 17(51).

Aurélio, B. H. F. (1986). Novo dicionário da língua Portuguesa. Nova Fronteira.

Bergamini, C. W.(1990). Desenvolvimento de Recursos Humanos: uma estratégia de desenvolvimento organizacional. Atlas. 
Research, Society and Development, v. 10, n. 5, e7110514364, 2021

(CC BY 4.0) | ISSN 2525-3409 | DOI: http://dx.doi.org/10.33448/rsd-v10i5.14364

Cabral, G. (2014). Maslow e as necessidades humanas. www.mundoeducacao.com. pisoclogia.maslow-as-necessidades-humanas

Castro, A. P.(2002). Manual de gestão de pessoas e equipes: Estratégias e tendências. Gente.

Caravantes, G.; Panno, C.\& kloeckner, M. (2005). Administração: teorias e processo. Pearson.

Chiavenato, I. (1999). Recursos Humanos. Atlas.

Chiavenato, I. (1994). Administração, teoria, processo e prática. Makron Books.

Chiavenato, I (2003). Introdução à Teoria Geral da Administração.Campus,

Gil, A. C.(2008). Gestão de Pessoas. Enfoque nos papéis profissionais. Atlas.

Gil, A. C.(2008). Métodos e Técnicas de Pesquisa Social. Atlas.

Maximiano, A.C. A.(2006). Teoria geral da administração: da escola científica à competitividade na economia globalizada. Atlas.

Maximiano, A. C. A.(2009). Introdução à Administração. Atlas.

Oliveira, S. L. de. Sociologia das organizações: uma analise do homem e das empresas no ambiente competitivo.

Oliveira, C.(2014). Escola das Relações Humanas. http://www.professorcezaar.adm.br.

Schermerhorn, J. R.; Hunt, J. G. \& Osborn, R. N. (1998). Fundamentos de comportamento organizacional. Bookman.

Silva. E.L. \& Menezes. E.M. (2001). Metodologia da pesquisa e elaboração de dissertação. Laboratório de Ensino a Distância da UFSC.

SILVA, R. O. (2001). Teorias da administração. Pioneira Thomson Learning.

Reinaldo W. G.; Borges, G. R. \& Santos, E. G. (2016). Determinantes da Desmotivação no Trabalho: uma investigação teórica e empírica. Revista de Administração de Roraima-UFRR, 6 (1), 4-17.

Robbins, S.. P. (2005). Comportamento Organizacional. Pearson Prentice Hall.

Vecchio, R. P. (2012). Comportamento Organizacional: conceitos básicos. Cengage Learning. 